EESTI NSV TEADUSTE AKADEEMIA TOIMETISED. KEEMIA ИЗВЕСТИЯ АҚАДЕМИИ НАУК ЭСТОНСКОЙ ССР. ХИМИЯ PROCEEDINGS OF THE ACADEMY OF SCIENCES OF THE ESTONIAN SSR. CHEMISTRY

$1985,34,3$

\title{
КОРРЕЛЯЦИЯ ПРЕДЕЛЬНЫХ КОЭФФИЦИЕНТОВ АКТИВНОСТИ НЕЭЛЕКТРОЛИТОВ С ИХ СВОЙСТВАМИ
}

\author{
(Представил О. Эйзен)
}

Термодинамические свойства растворов полярных неэлектролитов лишь в редких случаях (напр., при отсутствии специфического взаимодействия) могут быть предсказаны чисто теоретическим путем. Поэтому для растворов со сложным характером межмолекулярного взаимодействия широкое развитие получили полуэмпирические зависимости. Обычно они основаны на принципе линейности свободных энергий и описываются полипараметрическими линейными уравнениями, каждый параметр которых учитывает определенный вид межмолекулярного взаимодействия.

B $\left[{ }^{1,2}\right]$ показано, что коэффициенты распределения и предельные коэффициенты активности различных классов органических соединений удовлетворительно коррелируют посредством линейного полипараметрического уравнения

$$
y=A_{0}+\sum_{i=1}^{n} A_{i} x_{i}
$$

в которое, согласно [3], в качестве коррелирующих параметров $x_{i}$ введены поляризуемость, полярность, нуклеофильность (основность) и электрофильность (кислотность), а также параметр растворимости (плотность когезионной энергии) растворителя.

В настоящей работе показано, что аналогичный подход применим для описания зависимости между свойствами неэлектролитов различных классов и их предельными коэффициентами активности $\left(\gamma^{\infty}\right)$ в кислородсодержащих соединениях (представителях одно- и двухатомных фенолов, кетонов, простых и сложных эфиров), т. е. показана возможность корреляции $\gamma^{\infty}$ со свойствами не только растворителей, но и растворенных веществ.

Обработке подвергались полученные нами экспериментальные данные о $\gamma^{\infty}$ углеводородов, их галоген- и нитропроизводных, спиртов, кетонов, простых и сложных эфиров в 2-пропилфеноле, 4-пропилфеноле, 2,4-диизопропилфеноле, тимоле, 2-изобутилфеноле, 4-бутилфеноле, 4-изобутилфеноле, 2,4-ди-трет-бутилфеноле, 4-амилфеноле, гваяколе, 2,6 -диметоксифеноле, бутилфениловом эфире, метилсалицилате, бензофеноне $\left[{ }^{4}\right]$, а также данные $\left[{ }^{5,6}\right]$ о $\gamma^{\infty}$ в резорцине, 5-метилрезорцине и их диметиловых эфирах.

Использовали четырехпараметрическое уравнение в форме:

$$
\ln \gamma_{298}^{\infty}=A_{0}+A_{1} f(n)+A_{2} f(\varepsilon)+A_{3} B+A_{4} E,
$$

где, согласно [3], брали $f(n)=\left(n^{2}-1\right) /\left(n^{2}+2\right) \quad(n-$ показатель преломления $), f(\varepsilon)=(\varepsilon-1) /(2 \varepsilon+1)(\varepsilon-$ диэлектрическая проницаемость), 
Свойства растворенных соединений

\begin{tabular}{|c|c|c|c|c|c|}
\hline Номер & Соединение & $n_{D}$ & $\varepsilon$ & $B$ & $E$ \\
\hline $\begin{array}{r}1 \\
2 \\
3 \\
4 \\
5 \\
6 \\
7 \\
8 \\
9 \\
10 \\
11 \\
12 \\
13 \\
14 \\
15 \\
16 \\
17 \\
18 \\
19 \\
20 \\
21 \\
22 \\
23 \\
24\end{array}$ & $\begin{array}{l}\text { Пентан } \\
\text { Гексан } \\
\text { Гептан } \\
\text { Октан } \\
\text { 2-Пентен } \\
\text { 1-Гексен } \\
\text { 1-Гептен } \\
\text { Циклогексан } \\
\text { Бензол } \\
\text { Толуол } \\
\text { Хлороформ } \\
\text { Тетрахлорметан } \\
\text { Дихлорэтан } \\
\text { Тетрахлорэтан } \\
\text { 1-Хлорпропан } \\
\text { Нитрометан } \\
\text { Метанол } \\
\text { Этанол } \\
\text { 2-Пропанол } \\
\text { Ацетон } \\
\text { Метилэтилкетон } \\
\text { Этиловый эфир } \\
\text { Диизопропиловый эфир } \\
\text { Этилацетат }\end{array}$ & $\begin{array}{l}1,3575 \\
1,3749 \\
1,3877 \\
1,3974 \\
(1,3715) \\
1,3879 \\
1,3998 \\
1,4262 \\
1,5011 \\
1,4969 \\
1,4180 \\
1,4603 \\
1,4451 \\
1,4943 \\
1,3880 \\
1,3819 \\
1,3286 \\
1,3614 \\
1,3773 \\
1,3588 \\
1,3785 \\
1,3527 \\
1,3689 \\
1,3724\end{array}$ & $\begin{array}{c}1,844 \\
1,890 \\
1,924 \\
1,948 \\
(2,100) \\
(2,100) \\
2,100 \\
2,023 \\
2,284 \\
2,379 \\
4,806 \\
2,238 \\
10,360 \\
8,200 \\
7,700 \\
38,57 \\
32,63 \\
24,30 \\
18,3 \\
20,74 \\
18,51 \\
4,335 \\
3,88 \\
6,02\end{array}$ & $\begin{array}{c}0 \\
0 \\
0 \\
0 \\
- \\
- \\
- \\
0 \\
48 \\
58 \\
14 \\
0 \\
40 \\
- \\
(59) \\
65 \\
218 \\
235 \\
236 \\
224 \\
209 \\
280 \\
293 \\
181\end{array}$ & $\begin{array}{l}0 \\
0 \\
0 \\
0 \\
- \\
- \\
- \\
0 \\
2,1 \\
1,3 \\
3,3 \\
0 \\
2,99 \\
0 \\
0 \\
5,15 \\
14,94 \\
11,57 \\
8,70 \\
2,13 \\
1,35 \\
0 \\
0 \\
16\end{array}$ \\
\hline
\end{tabular}

$B$ - нуклеофильность, $E$ - электрофильность. Расчеты проводили на ЭВM EC 1022 по стандартной программе USER-01.

Свойства чистых растворенных веществ, необходимые для расчетов (табл. 1), брали в основном из $[3,7,8]$, а для некоторых соединений (алкенов, хлорпроизводных углеводородов), для которых эти данные в литературе отсутствуют, их условно принимали равными соответствующим значениям для ближайших гомологов (в табл. 1 заключены в скобки).

Полученные коэффициенты регрессии $A_{i}$, а также коэффициенты корреляции (r) и остаточная дисперсия величин $\ln \gamma_{298}^{\infty}(s)$ показывают (табл. 2), что между $\ln \gamma^{\infty}$ и свойствами растворенных соединений существует явная взаимосвязь, но в некоторых случаях корреляцию можно считать лишь удовлетворительной. Так, наименьшие значения $r(r \leqslant 0,80)$ наблюдаются при использовании в качестве нелетучего растворителя соединений, не содержащих в молекуле $\mathrm{OH}$-группы и не склонных к самоассоциации посредством образования Н-связи. $\ln \gamma^{\infty}$ в этих растворителях вообще варьируется значительно меньше, чем в фенолах. При этом $\ln \gamma^{\infty}$ зависит от нуклеофильности растворенного вещества несущественно, а коэффициенты $A_{4}$, отражающие влияние электрофильности на $\ln \gamma^{\infty}$, обычно положительны. Кроме того, $r$ и $s$ в значительной степени зависят от набора использованных веществ. Наибольшие расхождения экспериментальных и рассчитанных по корреляционному уравнению значений $\ln \gamma^{\infty}$ имеют место для растворов тетрахлорэтана и спиртов. Включение данных о $\ln \gamma^{\infty}$ спиртов $\mathrm{C}_{1}-\mathrm{C}_{3}$ во всех случаях дает значительное ухудшение $r$ и увеличение $s$ (табл. 3). Корреляция значительно улучшается при исключении данных о свойствах растворенных соединений, принятых по свойствам гомологов. 


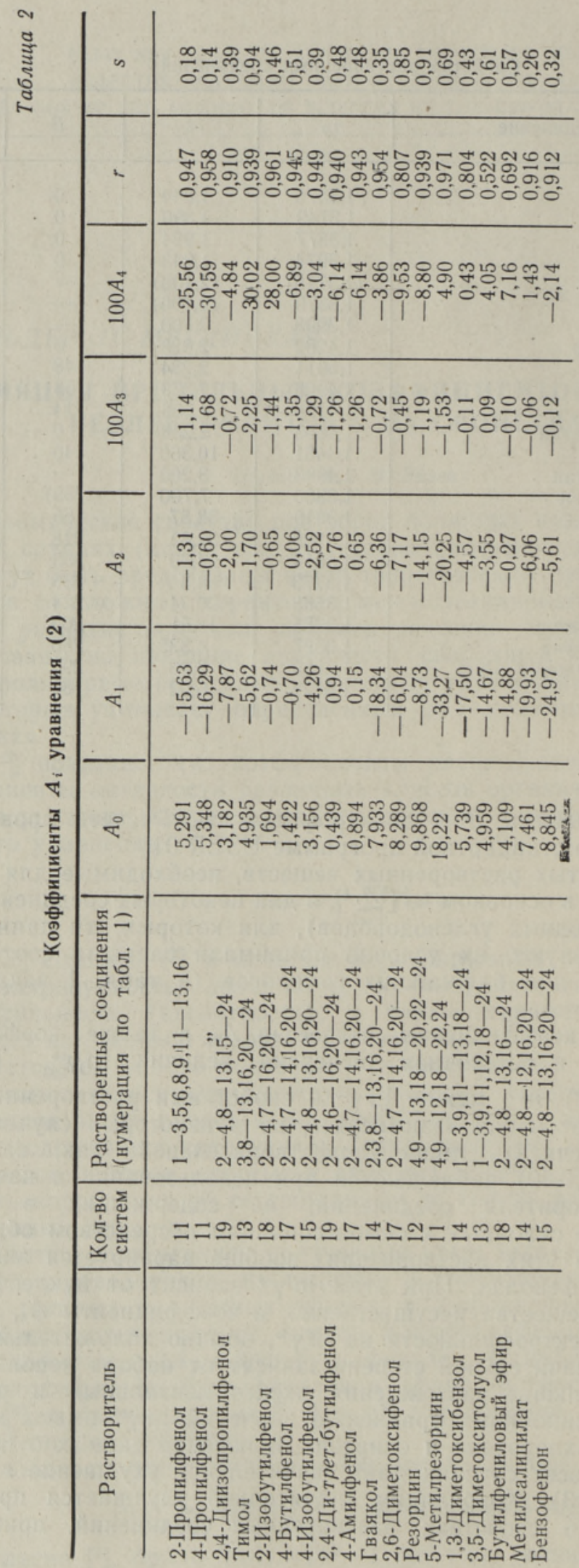


Сравнение $\boldsymbol{r}$ и $\boldsymbol{s}$ для уравнения (2)

при включении данных о $\ln \gamma^{\infty}$ спиртов $\mathrm{C}_{1}-\mathrm{C}_{3}$

\begin{tabular}{l|c|c|c|c|c|c}
\hline \multirow{2}{*}{ Растворитель } & \multicolumn{3}{|c|}{ Без спиртов } & \multicolumn{3}{|c}{ Со спиртами } \\
\cline { 2 - 7 } & $\begin{array}{c}\text { Кол-во } \\
\text { точек }\end{array}$ & $r$ & $s$ & $\begin{array}{c}\text { Кол-во } \\
\text { точек }\end{array}$ & $r$ & $s$ \\
\hline & 18 & 0,961 & 0,46 & 21 & 0,931 & 0,60 \\
2-Изобутилфенол & 17 & 0,945 & 0,51 & 20 & 0,907 & 0,63 \\
4-Бутилфенол & 15 & 0,949 & 0,39 & 18 & 0,898 & 0,66 \\
4-Изобутилфенол & 14 & 0,916 & 0,26 & 17 & 0,714 & 0,53 \\
Метилсалицилат & 15 & 0,912 & 0,32 & 18 & 0,772 & 0,51 \\
Бензофенон & & & & &
\end{tabular}

Для проверки возможности улучшения корреляции путем введения дополнительных параметров были проведены аналогичные расчеты, в которых в качестве пятого и шестого коррелирующих параметров использовали параметр растворимости (ठ) и парциальную избыточную энтропию смешения $\left(\bar{S}^{E}\right)$. При этом $\delta$, характеризующую плотность когезионной энергии, принимали равной $\left[\left(\Delta H^{v}-R T\right) / V\right]^{0,5}\left(\Delta H^{v}-\right.$ теплота испарения, $V$ - мольный объем), а $\bar{S}^{E}$ рассчитывали на основе экспериментальных данных [ $\left.{ }^{4}\right]$ из температурной зависимости $\ln \gamma^{\infty}$. Однако улучшение корреляции в этом случае оказалось незначительным (обычно $\sim 0,05)$, что говорит о нецелесообразности введения этих параметров в уравнение (2).

Таким образом, предельные коэффициенты активности широкого набора органических соединений удовлетворительно коррелируют посредством четырехпараметрического уравнения, в котором коррелирующими параметрами являются свойства чистых растворенных соединений, учитывающие в эмпирической форме их способность к неспецифической и специфической сольватации. По нашему мнению, константы $A_{i}$ (табл. 2) могут быть использованы для оценки коэффициентов активности и других неэлектролитов в вышеуказанных кислородсодержащих соединениях, но при этом, естественно, большой точности ожидать нельзя.

\section{ЛИТЕРАТ УРА}

1. Макитра Р. Г., Пириг Я. Н., Фильц Д. И. Влияние свойств растворителей на коэффициенты распределения. V. Извлечение уксусной и пропионовой кислот из водной среды органическими растворителями. - Реакц. способн. орган. соед., 1979, 16, вып. 2 (58), 261-272.

2. Макитра Р. Г., Мельдер Л. Н., Пириг Я. Н., Эббер А. В. Корреляция предельных коэффициентов активности сложных эфиров и кетонов с характеристиками растворителей. - Укр. хим. ж., 1983, 49, № 4, 367-372.

3. Koppel, I. A., Palm, V. A. The influence of the solvent on organic reactivity In: Advances in Linear Free Energy Relationships, Chapter 5. London, New York, 1972, 203-280.

4. Мельдер Л. Н., Метлицкая О. Ф. Предельные коэффициенты активности органических соединений в некоторых фенолах, кетонах и эфирах. - Ж. прикл. хим., (в печати).

5. Арро М. А. Избыточные термодинамические функции смешения органических соединений с резорцином и 5-метилрезорцином. - Тр. Таллин. политехн. ин-та, 1983, № 543, 25-33.

6. Арро М. А. Избыточные термодинамические функции смешения органических соединений с 3,5-диметокситолуолом, - Тр. Таллин. политехн. ин-та, 1983, № $543,19-23$. 
7. Коппель И. А., Паю А. И. Параметры общей основности растворителей. - Реакц. способн. орган. соед., 1974, 11, вып. 1(39), 121-138.

8. Коппель И. А., Паю А. И. Расширенная шкала параметров электрофильности растворителей. - Реакц. способн. орган. соед., 1974, 11, вып. 1(39), 139-143.

\section{Институт химии}

Академии наук Эстонской ССР

Таллинский политехнический институт
Поступила в редакцию

3/I 1985

L. MOLDER, O. METLITSKAJA

\section{MITTEELEKTROLUUTIDE OMADUSTE NING LOPMATUL LAHJENDUSEL MÃ̆RATUD AKTIIVSUSTEGURITE VAHELINE SÖLTUVUS}

On näidatud, et eri ühendiklassidesse kuuluvate mitteelektrolüütide aktiivsustegurid lôpmatul lahjendusel orgaanilistes hapnikuühendites (ühe- ja kahealuselistes fenoolides, ketoonides, eetrites ja estrites) on korreleeritavad lahustunud ainete omadustega. On toodud nelja muutujaga lineaarvõrrandi regressioonikordajad, kui võrrandi sisendparameetriteks on lahustunud aine polariseeritavus, polaarsus, nukleofiilsus ja elektrofiilsus.

\section{MOLDER, O. METLITSKAYA}

\section{CORRELATION BETWEEN THE LIMITING ACTIVITY COEFFICIENTS OF NONELECTROLYTES AND THEIR PROPERTIES}

The possibility of correlation between the limiting activity coefficients of various nonelectrolytes and their properties in oxygen-containing compounds as solvents (mono- and two-hydric phenols, ketones, ethers and esters) has been shown. The linear four-parameter equation containing polarity, polarizability, nycleophility and electrophility as correlating parameters is used for calculations. The coefficients of correlation equation are tabulated. 